This is the author's final, peer-reviewed manuscript as accepted for publication. The publisher-formatted version may be available through the publisher's web site or your institution's library.

\title{
Policy effects of the elasticity of substitution across labor types in life cycle models
}

Steven P. Cassou, Arantza Gorostiaga, Iker Uribe Zubiaga

\section{How to cite this manuscript}

If you make reference to this version of the manuscript, use the following information:

Cassou, S. P., Gorostiaga, A., \& Uribe Zubiaga, I. (2013). Policy effects of the elasticity of substitution across labor types in life cycle models. Retrieved from http://krex.ksu.edu

\section{Published Version Information}

Citation: Cassou, S. P., Gorostiaga, A., \& Uribe-Zubiaga, I. (2013). Policy effects of the elasticity of substitution across labor types in life cycle models. Economic Modelling, 35, 59-70.

Copyright: @ 2013 Elsevier B.V.

Digital Object Identifier (DOI): doi:10.1016/j.econmod.2013.06.021

Publisher's Link: http://www.sciencedirect.com/science/article/pii/S0264999313002393

This item was retrieved from the K-State Research Exchange (K-REx), the institutional repository of Kansas State University. K-REx is available at http://krex.ksu.edu 


\title{
Policy effects of the elasticity of substitution across labor types in life cycle models*
}

\author{
Steven P. Cassou \\ Kansas State University \\ Arantza Gorostiaga \\ Universidad del País Vasco, UPV/EHU \\ Iker Uribe Zubiaga \\ Universidad del País Vasco, UPV/EHU
}

June 11, 2013

\begin{abstract}
This paper investigates how the production function elasticity of substitution across different labor types impacts the results of policy analysis in multiperiod lived agent overlapping generations models. We critique and investigate the popular structure that simply assumes that workers with different age, experience or education are perfectly substitutable in production. This structure is inconsistent with empirical evidence of production complementarities. We couch our findings in the context of two types of policy reforms: a social security reform and a tax reform. These reforms were chosen in part because of the large interest in them, but also because of their differing effects on life cycle decisions. We find that ignoring production complementarity may influence the conclusions of policy analysis.
\end{abstract}

*We would like to thank participants at ASSET Conference 2011, XXXV Simposio de la Asociación Española de Economía, CEF 2011 Conference. Some of this research was supported by the Spanish Ministry of Education and Science, grant number ECO200909732 and Basque Government grant IT-793-13. Cassou would also like to acknowledge the support and hospitality of Ikerbasque and Universidad del País Vasco, UPV/EHU. 
JEL Classification: H2; E6

Keywords: Labor complementarity; overlapping generations model; fiscal policy reform; social security reform.

\section{Introduction}

Recent research into dynamic fiscal policy has shown considerable ability to handle complex overlapping generations models with multiperiod lived agents who participate in rich economies. ${ }^{1}$ Most of this work uses model formulations where workers of different age, experience or education are perfect substitutes in the production of goods. However, this formulation conflicts with a large empirical literature which finds that skilled and unskilled labor and more and less experienced workers are complementary in production. ${ }^{2}$ In this paper, we investigate how modeling assumptions about the elasticity of substitution across labor types that are made by a researcher can impact the outcome of policy analysis. ${ }^{3}$ To investigate this, we use two types of policy reforms, a social security reform and an income tax reform, to build intuition for understanding the impact of the production function elasticity of substitution. These reforms were chosen in part because of the large interest in them, but also because of their differing effects on life cycle decisions. We find that ignoring production complementarity can impact the conclusions

\footnotetext{
${ }^{1}$ Some of the earliest work on multiperiod lived agent overlapping generations models was carried out by Auerbach and Kotlikoff (1987) using perfect foresight models. Later work extended this modeling structure in a number of important ways. Some of the papers that are most relevant to our policy exercises are the following: İmrohoroğlu, İmrohoroğlu and Joines, (1995), Huggett (1996), Conesa and Krueger (1999, 2006), Huggett and Ventura (1999), Ventura (1999) and Rojas (2005, 2009), among others.

${ }^{2}$ Katz and Murphy (1992) found point estimates for the elasticity of substitution between skilled and unskilled labor of 1.41. Other studies, including Heckman, Lochner, and Taber (1998a), Krussel et al. (2000) and Blankenau and Cassou (2010) also find estimates close to this value. The literature estimating production elasticities between young and old workers is less extensive but work by Murphy and Welch (1992), Card and Lemieux (2001) and Ottaviano and Peri (2011) find the elasticity of subsitutition between young and old workers is around 5 .

${ }^{3}$ Our exercise is similar to one carried out by İmrohoroğlu and Kitao (2009) who investigated how the labor supply elasticity impacted conclusions about the effect of social security reform. A related exercise by Hansen and İmrohoroğlu (2009) investigates two mechanisms for acquiring skill. However, that study still uses a single effective labor type in production with relatively skilled agents simply having more of it.
} 
of policy analysis.

A few recent papers, such as Heckman, Lochner and Taber (1998b), Taber (2002), Rojas (2005, 2009) and Krueger and Ludwig (2013), have begun to investigate production functions in which workers with different productivity are less than perfectly substitutable, but considerable work still needs to be done. Our paper considers two types of labor input and explores two foundations for these labor types. One foundation, which we refer to as the experienced based labor structure, assumes that there are less and more experienced workers. Agents become experienced workers after participating in the labor force for a period of time. ${ }^{4}$ The second foundation posits that agents are born into a skill class and remain there for the rest of their working careers. Under this later mechanism, which we refer to as the ability based labor structure, agents might be naturally endowed with different abilities or might acquire skills early in life through education. ${ }^{5}$

We wish to emphasize that this paper does not aim to study in depth the impact of specific policy reforms, but rather to show how a researcher's assumptions about the elasticity of substitution might impact results of a reform. That said, for the sake of clarity, we do focus on two specific policy reforms to flesh out the impact that the elasticity of substitution assumption can have. These policy reforms include, a social security reform and an income tax reform. The reforms are investigated by including an income tax and social security system in the baseline model formulation and calibrating the model under each human capital structure to match the U.S. economy. Next, each baseline formulation is reformed and each reform is then compared to the baseline by computing positive and normative statistics such as changes in output and welfare. These changes in the economic statistics

\footnotetext{
${ }^{4}$ It is also useful to point out that there are many other life cycle studies, including Auerbach and Kotlikoff (1987), Hubbard and Judd (1987), İmrohoroğlu, İmrohoroğlu and Joines (1995) and one of the models in Conesa and Krueger (1999), that model effective labor as growing over time through a type of experience based structure. In these papers, experience accumulates through an exogenous age related productivity parameter. More recently, Peterman (2012), Kapička (2012) and Krueger and Ludwig (2013) study optimal taxation issues in frameworks where human capital and labor productiviy are endogenously determined. However, most of these papers, unlike Rojas $(2005,2009)$ and Krueger and Ludwig (2013), model more and less skilled labor as perfectly substitutable in production.

${ }^{5}$ Most of the empirical literature that estimates the elasticity of substitution between skilled and unskilled labor uses education levels to group individuals into skilled and unskilled labor, with skilled labor consisting of individuals with a college degree and unskilled individuals as having less than a college degree.
} 
are compared across elasticity values to see how this parameter impacts the assessment of policy reform.

For our models, we find that production complementarity can be important for the results of a social security reform but is not very important for tax reforms. Both reforms impact the same economic margins and the ultimate differences arise due to differences in how the two reforms impact the incentives for providing labor over an agent's lifetime. Furthermore, a demand side feedback effect is present and this demand side feedback results in a large range in the equilibrium effects for the social security reform. In particular, the demand side effect is connected to the elasticity of substitution across labor types and the change in the relative supply of each type of labor after the reform. Therefore production elasticities in the empirical range might imply quite different equilibrium results than the zero elasticity value implicitly used in most of the earlier studies.

To understand these results more thoroughly, first consider a reform that completely eliminates the pension system. After the reform, agents need to increase their savings to cover their retirement. This induces a large increase in the capital stock which impacts the marginal product of the two labor types. When human capital is modeled as arising via experience, agents choose the best life cycle labor profile which takes into account their transition from less to more experienced labor later in life, and this means that the results of the changes in labor supply can differ substantially with different elasticities of labor in production. In particular, the large changes in the relative labor supply of older workers allow the demand side feedback effect to enter which makes the results sensitive to the elasticity of substitution between young and old labor in production. When human capital is modeled as arising via an ability endowment things are different. The social security reform still requires them to increase their savings to cover their retirement, and this induces a large increase in the capital stock which impacts the marginal products of the two labor types. However, because agents spend their entire life in their skill class, the impact on the life cycle labor profile for both agents are similar which reduces the demand feedback effect, and the outcome of the policy change is largely the same for all production elasticities.

On the other hand, when investigating a tax reform that reduces the degree of progressivity, the modeling structure for human capital does not produce as varied outcomes. This is in part because the biggest effects on the labor market arise from the lower marginal tax rates on labor. Although this 
channel produces large increases in both types of labor supplies, it tends to do it in a relatively balanced way, so there are no large changes in the relative amounts of the two labor types. Furthermore, the savings channel is smaller than in the social security reform and this in turn reduces the life cycle labor effects resulting in a reduced demand effect for both the ability endowment labor structure and the experience based labor structure. It is true that the case when human capital is modeled as arising from experience produces larger changes in the life cycle labor profile than the case where human capital arises via ability endowment. However, the effects are relatively small in comparison to the social security reform.

Taken as a whole, this analysis shows that production function elasticities can have an impact on the results of a policy reform. Furthermore, the results found here provide insight into how policy reform results may be impacted in other labor foundation structures. One simple way to put the results here is to note that if the policy reform has an impact on the ratio of the two worker types, then the labor elasticity matters because of the demand side feedback effect. We believe this insight carries over to other labor foundation structures, such as one where labor arises through an explicitly modeled education sector. If a policy reform results in a change in the ratio of the two labor types, then the value of the elasticity of substitution will have an impact on the quantitative results. Conversely, if the policy reform does not impact the ratio of the two labor types, then the value of the elasticity will be negligible. Researchers need to understand how their elasticity choices can impact their results and should be careful to justify why a particular assumption is suitable for the study at hand.

To present these results in a clear format, we have organized the paper as follows. Section 2 presents the models. This section is broken down into subsections to highlight where the models are the same and where they differ. Section 3 describes how we calibrated the models. Then, in sections 4 and 5 , results of a social security reform and a tax reform are evaluated. Finally, section 6 discusses insights learned from our analysis and how to use these insights for thinking about other economic models. Section 7 concludes.

\section{The Model Economies}

The objective of this paper is to investigate the effect that the production function elasticity of substitution across worker types has on the results of 
policy analysis. We investigate this elasticity under two different labor foundation structures. To make things clear, we have organized this section into three subsections. The first subsection describes most of the model details. The second subsection describes the two different labor foundations under which the elasticity of substitution is explored. The third subsection then provides a formal definition of the competitive equilibrium so that all the details for how the models are put together are clear.

\subsection{Basic Set-up}

For the most part, the model is a standard general equilibrium life cycle model in which time is discrete. Because of this standard structure, this subsection breaks things down into subsections using a familiar format. We begin by describing the demographic structure, then the consumer sector, the production sector and the government sector are described in turn.

For our analysis, we focus on the steady state results. Even with this focus on steady state results, we find it convenient to use a subscript $t$ to indicate time in the description of the model in order to be clear about the timing of decisions made by individuals within a generation. Later we will drop the $t$ notation when the model structure is clear.

\subsubsection{Demographics}

At each date $t=0,1, \ldots$, there are $J$ overlapping generations of agents. This cross section of agents arises because of a continuum of new agents being born at each period $t$. The population growth rate is assumed to be constant and equal to $n$. In addition, agents live a maximum of $J$ periods, but face a positive probability of death every period. We denote the survival probability by $\psi_{j}=\operatorname{prob}($ alive at $j+1 \mid$ alive at $j$ ) where the subscript $j$ is used to indicate the age of an agent. At age $J$, all surviving agents of that generation die, which we indicate with $\psi_{J}=0$. We let the fraction of agents of age $j$ be denoted by $\mu_{j}$ and assume the demographic structure is stable in the sense that $\mu_{j}$ is constant over time. Under these assumptions it follows that $\mu_{j}=\frac{\psi_{j}}{1+n} \mu_{j-1}$. 


\subsubsection{Consumers}

At birth agents are endowed with no assets but are endowed with one unit of time in each period of their life which they allocate to leisure or to labor supply. They use their labor income to purchase consumption goods or invest in assets which can be sold at a later date to purchase consumption goods. Households pay consumption and income taxes and, during their working lives, they also pay a social security tax. Workers retire at age $j_{r}$ and receive social security payments for the rest of their lives.

Workers are assumed to be heterogeneous with regard to their labor productivity which depends on their type. We will describe the structure for how a worker's productivity level is determined below, but for now it is sufficient to recognize that there are two types of workers: type 1 and type 2 . We will distinguish an agent's type with the notation $i$, where $i=1,2$. We will let $\eta_{i}$, indicate the productivity component associated with ability $i$ and let $\varepsilon_{j}$, for $j=1, \ldots J$, denote an age-specific labor productivity. This age specific productivity component is such that agents beyond the retirement age $j_{r}$ have $\varepsilon_{j}=0$. Finally, agents of type $i$ will receive at $t$ a wage per effective unit of labor, $w_{i, t}$. These assumptions together imply that an agent of type $i$ and of age $j$ who provides $\ell_{i, j, t}$ units of labor, will receive pre tax labor income equal to $\varepsilon_{j} \eta_{i} w_{i, t} \ell_{i, j, t}$ at time $t$.

At any date, households can be characterized by a state variable $\left(a_{i, j, t}, i, j\right)$ where $a_{i, j, t}$ denotes asset holdings for an agent of type $i$ and age $j$ at time $t$. At time $t$, an $\left(a_{i, j, t}, i, j\right)$ agent chooses consumption, labor and assets subject to budget constraints given by

$$
\left(1+\tau_{c, t}\right) c_{i, j, t}+a_{i, j+1, t+1}=a_{i, j, t}+y_{i, j, t}-T\left(y_{i, j, t}\right)
$$

with

$$
y_{i, j, t}=\left\{\begin{array}{cc}
\left(1-\tau_{s s, t}\right) \varepsilon_{j} \eta_{i} w_{i, t} \ell_{i, j, t}+r_{t} a_{i, j, t} & \text { for } j<j r \\
S S_{t}+r_{t} a_{i, j, t} & \text { for } j \geq j r
\end{array}\right.
$$

and

$$
0 \leq a_{i, j+1, t+1}
$$

where $c_{i, j, t}, \ell_{i, j, t}$ and $y_{i, j, t}$ are consumption, labor supply and taxable income at $t$ for an agent of ability $i$ and age $j, \tau_{c, t}$ is the sales tax rate at time $t$, $r_{t}$ is the return on assets held between time $t$ and time $t+1, \tau_{s s, t}$ is the social security payroll tax, $S S_{t}$ is the social security pension and $T\left(y_{i, j, t}\right)$ is 
the amount of taxes paid at time $t$ for income level $y_{i, j, t}$. Households are assumed to be borrowing constrained.

Given these endowment and income constraints, agents make choices so as to maximize their preferences for consumption and leisure over their lifetimes given by

$$
E\left[\sum_{j=1}^{J} \beta^{j-1}\left(\prod_{\iota=1}^{j} \psi_{\iota}\right) u\left(c_{i, j, t}, \ell_{i, j, t}\right)\right],
$$

where $\beta$ is the discount factor. The utility function $u(c, \ell)$ is assumed to have a CES functional form,

$$
u(c, \ell)=\frac{\left[c^{\gamma}(1-\ell)^{1-\gamma}\right]^{1-\sigma}}{1-\sigma}, \text { for } \sigma \neq 1,
$$

where $0 \leq \sigma$ and $\gamma$ measures the relative importance of consumption in utility. Under this utility function specification, the intertemporal elasticity of substitution is equal to, $\frac{1}{1-\gamma(1-\sigma)}$.

\subsubsection{Firms}

Firms in the economy operate a constant returns to scale production function which uses capital, $K_{t}$, and aggregate labor, $L_{t}$, to produce output, $Y_{t}$ according to

$$
Y_{t}=A K_{t}^{\alpha} L_{t}^{1-\alpha}
$$

where $0<\alpha<1$ and $A>0$. As usual, the parameter $\alpha$ can be interpreted as representing the share of output used to pay capital owners. We assume that there is no technological progress and, therefore, total factor productivity $A$ is constant over time. Also, capital is assumed to depreciate at rate $\delta$.

The aggregate labor input, $L_{t}$, is measured in efficiency units and depends on type 1 labor and type 2 labor according to,

$$
L_{t}=B\left[\lambda L_{1 t}^{1-\rho}+(1-\lambda) L_{2 t}^{1-\rho}\right]^{\frac{1}{1-\rho}}, \text { for } \rho \neq 1,
$$

where $0 \leq \rho$ and $L_{1 t}$ and $L_{2 t}$ denote efficiency units of labor of type 1 and labor of type 2, respectively. The inverse of the elasticity of substitution between labor of type 1 and labor of type 2 is equal to $\rho$. When $\rho=0$, labor of type 1 and labor of type 2 are perfect substitutes. Any value of $\rho$ larger than zero implies imperfect substitution between both types of labor. In addition, firms participate in competitive markets so that wage rates and capital rental rates equal their marginal products in production. 


\subsubsection{The government}

The government runs what can essentially be regarded as two separate balanced budget accounts. ${ }^{6}$ First, the government runs a pay as-you-go type social security system in which retirees obtain social security payments of $S S_{t}$ equal to $b_{t}$ percent of current average wage income. These payments are financed by payroll taxes at rate $\tau_{s s, t}$ which are just high enough to balance the social security budget.

The government also runs a balanced budget in its non social security budget which we will refer to as the federal budget. It is assumed that government spending at time $t$, denoted $G_{t}$, is exogenously given. This spending is financed through income taxes, $T\left(y_{t}\right)$, sales taxes, $\tau_{c, t}$, and accidental transfers, $T r_{t}$, arising from the unanticipated deaths of some agents of the economy.

We assume a progressive income tax system described by the policy rule suggested by Gouveia and Strauss (1994) under which taxes depend on taxable income, $y$, as follows,

$$
T(y)=\kappa_{0}\left[y-\left(y^{-\kappa_{1}}+\kappa_{2}\right)^{-\frac{1}{\kappa_{1}}}\right],
$$

where $\kappa_{0}, \kappa_{1}$ and $\kappa_{2}$ are parameters. Under this income tax policy rule, both marginal and average tax rates depend positively on taxable income. When $\kappa_{1}$ is equal to zero, the tax system is purely proportional. As $\kappa_{1}$ increases, the tax system becomes more progressive.

\subsection{Labor Foundations: Two Alternative Formulations}

The description of the model up to this point applies regardless of the foundations for the two types of labor. In our analysis we explore two foundations for the labor types. In the first version, which we will refer to as the ability endowment labor structure, we assume that agents are born as either unskilled (type 1) or skilled (type 2). Under this formulation, one may think of skills as related to education that occurs prior to entry into the labor force. Agents born into a particular ability class maintain this skill level throughout their life. We let $p_{i}$ indicate the probability of being born type $i=1,2$.

\footnotetext{
${ }^{6}$ Our usage of two different government budgets uses the structure and terminology used in the U.S. where in principle the Social Security Budget is kept separately from the Federal Budget.
} 
The second version, which we will refer to as the experience based labor structure, follows Rojas $(2005,2009)$ in assuming that some skills are acquired through work experience. Workers have no experience when they join the labor market. Workers with less than $j_{s}$ years of work experience are workers of type 1 under this formulation. After $j_{s}$ years at work, agents become experienced workers or workers of type 2 . Note that all agents of each generation are the same.

\subsection{The Competitive Equilibrium}

From this point on we will focus on stationary equilibria and thus it will be convenient to drop the time subscripts. Since there is still a small need to distinguish some variables at different dates, we will use a prime notation to indicate variables next period. So, for example, under this convention, $a$ will indicate asset holdings by an agent at the beginning of the period and $a^{\prime}$ will indicate asset holdings at the end of the period which will be held until the next period.

The first thing to note is that the model is transformed in the usual way by dividing aggregate variables by population size and using lower case variables to indicate per capita variables.

Definition. Given a demographic structure $\left\{\mu_{j}\right\}_{j=1}^{J}$ and policies $\left\{\tau_{c}, G, \tau_{s s}\right\}$, a steady state equilibrium is a collection of functions for the household $\{V(a, i, j), c(a, i, j)$

$\left.a^{\prime}(a, i, j), \ell(a, i, j), y(a, i, j)\right\}$, prices $\left\{r, w_{1}, w_{2}\right\}$, aggregate capital $K$, aggregate labor, $L$, efficiency units of labor of type $1, L_{1}$, efficiency units of labor of type $2, L_{2}$, social security replacement rate, $b$, social security pensions, $S S$, tax function, $T($.$) , transfers due to accidental bequests, T r$, and a law of motion for the distribution of agents $\Phi(a, i, j)$ such that,

1. Given prices, policies and initial conditions, $\left\{V, c, a^{\prime}, \ell, y\right\}$ are such that

$$
V(a, i, j)=\max _{\left\{c, a^{\prime}, \ell\right\}} u(c, \ell)+\beta \psi_{j} E V\left(a^{\prime}, i, j+1\right)
$$


subject to

$$
\begin{aligned}
\left(1+\tau_{c}\right) c(a, i, j)+a^{\prime}(a, i, j) & =a+y(a, i, j)-T[y(a, i, j)] \\
y(a, i, j) & =\left(1-\tau_{s s}\right) \varepsilon_{j} \eta_{i} w_{i} \ell(a, i, j)+r a \text { for } j<j_{r} \\
y(a, i, j) & =S S+r a \text { for } j<j_{r} \\
0 & \leq a^{\prime}(a, i, j) \\
c & \geqslant 0,0 \leq \ell \leq 1 \\
V(., ., J+1) & =0
\end{aligned}
$$

2. Prices are such that the representative firm maximizes profits

$$
\begin{aligned}
r & =\alpha A K^{\alpha-1} L^{1-\alpha}-\delta \\
w_{1} & =(1-\alpha) A K^{\alpha} L^{-\alpha} \frac{\partial L}{\partial L_{1}}=(1-\alpha) \lambda A K^{\alpha} L^{\frac{-\alpha \rho}{1-\rho}} L_{1}^{-\rho}, \\
w_{2} & =(1-\alpha) A K^{\alpha} L^{-\alpha} \frac{\partial L}{\partial L_{2}}=(1-\alpha)(1-\lambda) A K^{\alpha} L^{\frac{-\alpha \rho}{1-\rho}} L_{2}^{-\rho},
\end{aligned}
$$

with

$$
L=B\left[\lambda L_{1}^{1-\rho}+(1-\lambda) L_{2}^{1-\rho}\right]^{\frac{1}{1-\rho}}
$$

3. The social security tax and pension are such that,

$$
\begin{gathered}
S S=b \frac{w_{1} L_{1}+w_{2} L_{2}}{\sum_{j=1}^{j_{r}-1} \mu_{j}}, \\
\tau_{s s}\left(w_{1} L_{1}+w_{2} L_{2}\right)=S S \sum_{j=j_{r}}^{J} \mu_{j},
\end{gathered}
$$

4. Transfers are equal to accidental bequests,

$$
\operatorname{Tr}=\frac{\sum_{i, j}\left(1-\psi_{j}\right) a^{\prime}(a, i, j) \Phi(a, i, j)}{1+n}
$$

5. The government budget constraint holds

$$
G=\sum_{i, j} T[y(a, i, j)] \Phi(a, i, j)+\tau_{c, t} \sum_{i, j} c(a, i, j) \Phi(a, i, j)+(1+r) T r
$$


6. All markets clear,

- Goods market:

$$
\sum_{i, j} c(a, i, j) \Phi(a, i, j)+\sum_{i, j} a^{\prime}(a, i, j) \Phi(a, i, j)+G=A K^{\alpha} L^{1-\alpha}+(1-\delta) K
$$

- Capital market:

$$
K=\frac{\sum_{i, j} a^{\prime}(a, i, j) \Phi(a, i, j)}{1+n}
$$

- Labor market: in the ability endowment labor structure

$$
\begin{aligned}
L_{1} & =\sum_{j=1}^{j_{r}-1} \varepsilon_{j} \eta_{1} \ell(a, 1, j) \Phi(a, 1, j) \\
L_{2} & =\sum_{j=1}^{j_{r}-1} \varepsilon_{j} \eta_{2} \ell(a, 2, j) \Phi(a, 2, j)
\end{aligned}
$$

or, in the experience based labor structure

$$
\begin{aligned}
L_{1} & =\sum_{j=1}^{j_{s}} \varepsilon_{j} \eta_{1} \ell(a, 1, j) \Phi(a, 1, j) \\
L_{2} & =\sum_{j=j_{s}+1}^{j_{r}-1} \varepsilon_{j} \eta_{2} \ell(a, 2, j) \Phi(a, 2, j)
\end{aligned}
$$

7. The distribution $\Phi(a, i, j)$ is such that,

- in the ability endowment labor structure

$$
\begin{aligned}
& \text { For newborn agents, } \Phi(a, i, 1)= \begin{cases}p_{i} \mu_{1} & \text { if } a=0 \\
0 & \text { otherwise }\end{cases} \\
& \text { For } j>1, \Phi\left(a^{\prime}, i, j+1\right)= \begin{cases}\psi_{j} \Phi(a, i, j) & \text { if } a^{\prime}=a^{\prime}(a, i, j) \\
0 & \text { otherwise }\end{cases}
\end{aligned}
$$

- in the experience based labor structure 


$$
\begin{aligned}
& \text { For newborn agents, } \Phi(a, i, 1)= \begin{cases}\mu_{1} & \text { if } a=0 \text { and } i=1 \\
0 & \text { otherwise }\end{cases} \\
& \text { For } 1<j<j_{s} \text { or } j>j_{s}, \Phi\left(a^{\prime}, i, j+1\right)= \begin{cases}\psi_{j} \Phi(a, i, j) & \text { if } a^{\prime}=a^{\prime}(a, i, j) \\
0 & \text { otherwise }\end{cases} \\
& \text { For } j=j_{s}, \Phi\left(a^{\prime}, 2, j+1\right)= \begin{cases}\psi_{j} \Phi(a, 1, j) & \text { if } a^{\prime}=a^{\prime}(a, 1, j) \\
0 & \text { otherwise }\end{cases}
\end{aligned}
$$

\section{Calibration}

To understand the calibration procedure it is important to be clear about the objective of this paper. The objective is not to comment in depth about the impact of policy, but rather to comment about how a researcher's assumptions about the elasticity of substitution across labor types may impact their analysis of policy.

Because we conduct this analysis using two different labor foundations which have different parameters, the calibration exercise has to be suitably controlled as well. What we do, is to calibrate each model so that they match the same statistics. In effect, we are trying to mimic a situation where different researchers may each have their own model for the economy, but they agree on what statistics should be matched when calibrating their models.

For each version of the model, we calibrate a benchmark formulation that matches the U.S. economy in which there is a progressive income tax system and a pay-as-you-go social security system. We also calibrate the benchmark economy under different production elasticities across labor types.

We use a typical calibration strategy which picks some parameters from a set of values that are widely used in the macroeconomic literature, and we pick other parameters by ensuring that the model matches some "stylized facts" from the observed data. The parameter selection process works as follows.

Demographics. Agents in our economy are born when they are $20(j=1)$, and live at most until $100(J=81)$. The survival probabilities, $\psi_{j}$, are taken from the United States life tables in 2003 using the data for the total population. Agents retire at 65 years old $(j=46)$. The population growth rate is set equal to $1.1 \%$ which matches the long run U.S. population growth rate. 
Preferences. The discount rate, $\beta$, is set in order for the capital-to-output ratio to be 3.0 in the benchmark model economy as it is observed in the U.S. data. The weight for consumption in the utility function, $\gamma$, is calibrated so that on average, the portion of the time endowment devoted to work is 0.33 . Parameter $\sigma$ is set equal to 2 which implies that the intertemporal elasticity of substitution is equal to 0.75 and the average Frisch elasticity 1.4.

Technology. As is common in macroeconomic calibrations, $\alpha$ is set to 0.36 , which matches the long run participation of capital income in Gross Domestic Product (GDP) for the U.S. The depreciation rate, $\delta$, is chosen in order for the benchmark model economy to result in an investment share in GDP equal to 0.28 , as observed in the U.S. economy and the total factor productivity parameter, $A$, is set equal to one.

Government. The government spending parameter, $g$, is set to 0.17 , which is the percentage of total output consumed by the government in the U.S. economy. The consumption tax rate, $\tau_{c}$, is set equal to 0.052 , following Mendoza, Razin and Tesar (1994). The parameters $\kappa_{0}$ and $\kappa_{1}$ in the income tax policy rule, $T($.), are fixed to values found by Gouveia and Strauss (1994), while $\kappa_{2}$ is then set so that there is a balanced public budget. Finally, the social security payroll tax is set equal to $10.6 \%$, which matches the U.S. percentage once deducted the disability insurance portion. This implies a replacement rate, $b$, equal to $42 \%$.

Labor type and labor productivity. The age-specific productivity component, $\varepsilon_{j}$, is calibrated using values estimated in Hansen (1983) for male workers. The parameters related to the labor type are then assigned values that differ based on the model version.

In the ability endowment labor structure, $p_{1}$ is chosen to be equal to the percentage of the U.S. population with less than a college degree, according to Current Population Survey (CPS) data. The productivity component associated with skill levels, $\eta_{1}$ and $\eta_{2}$, are set following Storesletten, Telmer and Yaron (2004) to calibrate the model economy so that the variance of the logarithm of earnings for 20 year olds is equal to 0.27 .

In the experience based labor structure, it is assumed that agents become experienced workers after 15 years of work experience $\left(j_{s}=15\right)$ and the productivity component associated with labor types, $\eta_{1}$ and $\eta_{2}$, were both set equal to one. The reason for the later calibration is that differences in productivity that depend on age are already captured by $\varepsilon_{j}$.

We follow Rojas (2005) to calibrate parameters $\rho, B$ and $\lambda$ in the production function. We consider a range of values for $\rho$ between 0 and 4 . This 
range of values is consistent with the range of values found in both the labor literature that focuses on the elasticity of substitution between skilled labor and unskilled labor, as well as the literature that focuses on the elasticity of substitution between experienced and inexperienced workers. ${ }^{7}$ When $\rho=0$, workers of type 1 and workers of type 2 are perfect substitutes and their differences in productivity are already captured by the estimated values for $\varepsilon_{j}$ and the calibrated values of $\eta_{i}$. Therefore, we set $\lambda=0.5$, and we have $w_{1}=w_{2}$. We scale the economy size by setting $B=2$. This calibration of the benchmark economy then becomes the target for other parameterizations of $\lambda$ and $B$ under different values of $\rho$. For each $\rho$, we recalibrate $\lambda$ and $B$ so as to have exactly the same benchmark economy as in the case with $\rho=0$. In other words, the benchmark economy will be numerically the same for all the cases assuming different degrees of complementarity between labor of type 1 and labor of type 2. Therefore, potential differences in the impact of a policy reform will necessarily be due to the strategy adopted by the researcher to model labor complementarity.

Tables $1 \mathrm{a}$ and $1 \mathrm{~b}$ summarize the outcome of the calibration procedure for all the models. Table $1 \mathrm{a}$ is divided into three panels. The first panel provides information about the common calibration details while the next two panels provide information about parameters that are specific to the two versions of the model. Table $1 \mathrm{~b}$ then provides further parameters which reflect different production function formulations ranging from a perfectly substitutable case to one in which the elasticity of substitution is at the high end of the empirical range. Table $1 \mathrm{~b}$ is also broken into two panels with each panel representing parameter values associated with a different version of the model.

[INSERT TABLE 1a AND TABLE 1B HERE]

\section{Social Security Reform Results}

In this section we evaluate a social security reform policy under the different formulations for the model to see how sensitive the results are to the elasticity of substitution values. The social security reform we consider is one

\footnotetext{
${ }^{7}$ The skilled and unskilled labor elasticity literature includes Katz and Murphy (1992), Heckman, Lochner, and Taber (1998a), Krussel et al. (2000) and Blankenau and Cassou (2010) while the experienced and inexperienced labor elasticity literature includes Murphy and Welch (1992) Card and Lemieux (2001) and Ottaviano and Peri (2011).
} 
that has been explored by Conesa and Krueger (1999), Fuster, Imrohoroğlu and İmrohoroğlu (2007), İmrohoroğlu and Kitao (2009), Rojas (2009) and others, and consists of eliminating the social security system. Although other types of reform are worth considering in the right setting, we do not look at them here because the objective of this paper is not to make statements about policy reforms, but instead, to make statements about how the analysis of reforms can be impacted by the production function elasticity of substitution. Furthermore, although it is feasible to investigate transitional dynamics between baseline policies and post reform policies, we do not do this for the same reason. In what follows, we describe the pre and post reform steady states for the model and explain how the model structure impacts the outcome of a reform.

Table 2 and Figures $1 \mathrm{a}$ and $1 \mathrm{~b}$ summarize some of the key results for evaluating the impact modeling assumptions have on social security reform analysis.

\section{[INSERT TABLE 2 HERE]}

Table 2 is broken into two panels, with the upper panel focusing on the ability endowment labor structure and the lower panel focusing on the experience based labor structure. The first column of each panel presents the value that output, the capital to output ratio, the type 1 labor input, the type 2 labor input, average hours worked, interest rate and wage rate take in the benchmark economy. Columns 2 to 6 provide results of the post reform steady state for different values of the production elasticity. For each variable, except the interest rate, we report the percentage difference from the pre reform, or baseline, steady state. For the interest rate we report levels before and after the reform. So for instance, looking across the first row, we see that for the ability endowment labor structure model, the output level is 0.76 in the benchmark economy, while under perfectly substitutable labor inputs $(\rho=0)$, the post reform output is $25.0 \%$ higher than in the baseline model. The last row presents the consumption equivalent variation $(\mathrm{CEV})$. For the economy in column one, the $\mathrm{CEV}$ is $7.3 \%$, which means that this policy results in a utility increase that would be equivalent to a $7.3 \%$ increase in consumption from the pre policy change value.

To begin the analysis, let us start by intuitively recognizing how a social security reform impacts the economic variables. Elimination of the social security system does two direct things. It increases consumer disposable 
income because of the elimination of the social security tax and it requires that consumers accumulate their own portfolio of assets to cover their retirement. Taken together, these direct effects imply that most of the increased disposable income is plowed into savings and this increased savings consequently increases the capital stock. The higher capital stock then results in two effects for the labor supply. First, the higher capital stock increases the marginal products of both labor types and this accounts for the mostly larger labor values reported in Table 2. Second, the higher capital stock reduces the returns to savings and this lower return to savings produces an intertemporal labor reallocation effect which makes agents desire working later in life and spending more of their time at leisure in their younger years. Furthermore, the extent to which labor is reallocated to youth depends on the demand side of the labor market and, moreover, this demand side effect depends on the labor input modeling structure. As we show below, in cases in which labor types are relatively substitutable in production, the demand side of the labor market produces no offsetting effects from consumers who wish to work less when young. However, when labor types are relatively complementary in production, the demand side of the labor market produces effects which offset consumer desires. This offsetting effect has large implications in the experience based labor structure and this accounts for the very different implications for that model when labor types are complementary in production.

To see how these economic effects work, begin by looking at Table 2, and noting that the range for the output changes is from $25 \%$ to almost $30 \%$. These output gains arise from the increase in the capital stock and (in most cases) the increase in the labor inputs which we will explain in a moment. The second thing to notice is that the production elasticity of substitution is not important to the outcome of the ability endowment labor structure models. In all of these cases, the output gain is $25 \%$. However, the production elasticity of substitution is important for the experience based labor structure model. For this model, when the labor inputs are perfectly substitutable $(\rho=0)$, the output increase is on the low end, with a gain of $25.5 \%$, while when the labor inputs are relatively complementary $(\rho=4)$, the output gain is on the high end, with a gain of $29.8 \%$.

Moving on to the capital to output ratio row, we see that capital exhibits a similar pattern as output. Again, these magnitudes are consistent with other studies that consider similar theoretical frameworks and calibration targets. Since the numerator is the capital stock in these ratios, the fact 
that these percentage changes are positive indicates that capital expands somewhat more than output. This is not surprising because that input is impacted most directly by eliminating the social security system. Without social security, agents need to save for themselves for retirement and savings can only be accomplished through capital accumulation.

The impact of the production function elasticities on labor supply is quite different for the two labor foundations and arises because of the complicated cross effects on the labor market. As the table shows, under the ability endowment labor structure, the production elasticity of substitution results in very small effects on the labor supply and thus on output, while in the experience based labor structure, the production elasticity results in larger effects on the labor supply and thus on output.

To understand how these differences arise, let us work through the economics of the labor market in more detail. First recall that the effect of the higher need to save and the higher capital stock, is a lower return on capital and thus savings. This lower capital return then makes it less attractive for agents to work during their youth and then sit on their assets and let the interest income compound to build a portfolio for retirement. Instead, households react to the reform by substituting intertemporally labor supply so that agents want to use more of their time allocation early in life for leisure and devote more of their time allocation to work later in life. Next, consider how the labor structure plays into the desire to take more leisure when young and work more when old. The key to understanding the differences between the two structures originates from the demand side for labor. It can be shown that the wage ratio for labor of type 1 and labor of type 2 is given by

$$
\frac{w_{1}}{w_{2}}=\frac{\lambda}{1-\lambda}\left(\frac{L_{1}}{L_{2}}\right)^{-\rho}
$$

This equation implies that changes in the labor ratio induces changes in the relative wages. In particular, when $\rho>0$, a decline in $\frac{L_{1}}{L_{2}}$ results in an increase in $\frac{w_{1}}{w_{2}}$, and this demand effect can work against the supply effect induced by the low returns to savings.

Working through these labor market effects for the ability based labor structure, we will now argue that the demand side effect is negligible and this accounts for the similar equilibrium values under the different production elasticities. To understand why the demand side effect is negligible, one needs to actually start on the supply side. According to the modeling 
assumptions, both labor types experience the same life cycle productivity patterns which are summarized by Hansen (1983) and modeled by $\varepsilon_{j}$ and this is the one feature that dominates the intertemporal decisions. Other differences between the two labor types include the skill type productivity component $\eta_{i}$, which is calibrated so that skilled workers have more effective labor units at each date than unskilled workers, the wage rates received per effective labor unit $w_{i}$ and the progressivity of the tax system. Taken together, these differences imply that the two skill types have life cycle after tax labor income profiles that are close to perfect scalars of each other. This means that the intertemporal trade-offs arising from the low returns to capital faced by the two agent types are largely the same and both respond to the reform in the same way, resulting in $\frac{L_{1}}{L_{2}}$ staying fairly constant. This relatively constant $\frac{L_{1}}{L_{2}}$ then implies that relative wages are relatively constant no matter what the value for the production elasticity and this neutralizes the demand effect.

\section{[INSERT FIGURE 1a HERE]}

Both the similar intertemporal time allocation profiles between the two labor types and the lack of an effect from the production elasticity can be seen in Figure 1a which graphs the life cycle labor supply for the baseline economy and the two extreme post reform elasticity cases $(\rho=0$ and $\rho=4)$. Figure 1a consists of a pair of diagrams, with the first diagram representing the life-cycle labor supply for unskilled workers and the second diagram representing the life-cycle labor supply for skilled workers. In these plots we use a convention of plotting the baseline economy using a long dash, the perfectly substitutable labor inputs in production case $(\rho=0)$ using a short dash, and the relatively complementary labor inputs in production case $(\rho=4)$ using a solid line. One common feature of all the labor profiles is a flat, or constant, labor supply for the first few years of an agents working career. This arises because agents are constrained from borrowing. The date when the labor supply starts to increase occurs when the nonnegativity constraint on assets stops binding. To finance positive savings, agents increase their work effort. ${ }^{8}$

Figure 1a shows the post reform intertemporal substitution of hours worked, where agents tend to work less when young and more when old,

\footnotetext{
${ }^{8}$ This feature was also seen in other papers such as Conesa and Krueger (1999).
} 
for both agent types. ${ }^{9}$ Note also that the life-cycle labor supply profile is flatter after the reform because agents have to work considerably more over their working lives in order to accumulate their retirement portfolio. Further note, that both agent types have largely the same post reform intertemporal labor profile and this is what neutralizes the demand effect linked to the elasticity of substitution in production.

On the other hand, quite different labor outcomes arise in the experience based labor structure economies. This can be seen in both Table 2, which provides the aggregated less and more experienced labor inputs at each date, and Figure 1b, which provides the intertemporal labor provision for agents under different production elasticities. As Table 2 shows, the steady state post reform aggregate old (more experienced) labor input increases by between $15.3 \%$ and $21.5 \%$, depending on the production elasticity, while the young (less experienced) labor input exhibits a more varied outcome, with input changes ranging between $-3.5 \%$ and $7.0 \%$. Figure $1 \mathrm{~b}$ plots the labor inputs over the agent's life-cycle for the baseline economy and two post reform economies including the perfectly substitutable case $(\rho=0)$ and the relatively complementary case $(\rho=4)$. In this figure, we have used the same plotting convention as in Figure 1a. One obvious difference between the two figures is that only one diagram is needed to plot the life-cycle labor supply because there is only one agent who transitions from labor of type 1 to labor of type 2 midway, at age 35, through their working career. Thus the portion of the life-cycle labor supply curves for ages less than 35 corresponds to the less experienced labor supply while the portion of the curves for ages greater or equal to 35 correspond to the more experienced labor supply.

\section{[INSERT FIGURE 1b HERE]}

To understand the economics in the experience based labor structure economy, again recognize that the higher savings rate, increases the capital stock, which reduces capital returns and makes agents prefer to work less when young and more when old. However, in the experience based labor

\footnotetext{
${ }^{9} \mathrm{McGrattan}$ and Rogerson (2004) describe the lifetime pattern of hours worked per person in the US since World War II and find evidence of shifts from older people to younger people. They point out that a relevant factor for this lifecycle reallocation has been increases in social security benefits to retired workers. The reaction of hours worked that we find in our simulations of the social security reform are consistent with that evidence.
} 
structure economy, the demand side margin also comes into play for the intertemporal labor choice. The demand margin enters because agents are workers of type 1 when young and workers of type 2 when old. This means their labor income profile changes dramatically over their lifetimes and they will take this into account in choosing their life cycle labor profile. Now because agents supply less experienced labor when young and more experienced labor when old, changes in the life cycle labor profile create changes in $\frac{L_{1}}{L_{2}}$ which alters the relative wages and creates a demand effect which offsets the consumer's supply effect. Furthermore, this demand effect varies with the production elasticity of substitution, so that the entire equilibrium is impacted by this elasticity.

When more and less experienced workers are perfect substitutes $(\rho=0)$, relative wages do not change with the relative supply of less experienced workers. This means there is no demand effect from the production elasticity and the capital induced intertemporal labor reallocation approximately matches what occurs in the ability endowment labor structure. This can be seen in the $\rho=0$ plot in Figure 1b. On the other hand, when $\rho$ is positive, the pressure from the labor supply side to reduce time in production of less experienced workers, is partially offset by pressure from the labor demand side to keep balanced amounts of both types of labor inputs. In this case less experienced labor wage rates rise, which encourages more young labor. For large values of $\rho$, effects due to labor input complementarity more than offset the labor supply pressure and the general equilibrium effect results in an increase in less experienced labor hours. The $\rho=4$ plot in Figure $1 \mathrm{~b}$ exhibits these competing effects on the intertemporal labor profile. In particular, the high degree of complementarity between the two labor inputs encourages a larger young labor component than lower values of $\rho$. However, the low capital return effect, still produces a time preference for lower labor supply early in life. This effects manifests itself so that focusing only at on one type of labor, we see a skewness so that the bulk of that labor type comes later in the agent's lifetime. So in particular, the agent provides considerable more inexperienced labor when they are in their 30s as opposed to when they are in their 20 s and they provide more (relative to the perfectly elastic case) experienced labor when they are in their 60s than when they are in their $40 \mathrm{~s}$.

To summarize our results, we have shown that the structure for modeling labor types complementary impacts the results of a social security reform. When agents are born into their ability type, the main effect on labor alloca- 
tions arises from the low returns on capital which produces an intertemporal preference for providing labor later in life. On the other hand, when agents transition from less experienced labor to more experienced labor, a second effect has a significant impact on the equilibrium labor profile. This second effect comes from the demand side of the labor market. When production has labor elasticities that are relatively complementary, then the reduced desire for providing labor early in life is offset by higher wages for less experienced labor. This production effect can result in quite dramatic swings in an agent's intertemporal labor profile. Furthermore, these large effects on the labor supply are consistent with Rojas (2009) and result in large effects on the entire equilibrium outcome.

\section{Tax Reform Results}

In this section we investigate the impact of assumptions about the elasticity of substitution across labor types on the results of a tax reform. The particular tax reform we consider consists of a revenue neutral reform of the tax system from the baseline progressive tax system used in the calibration to a pure proportional tax system. Numerous studies, including Castañeda, DíazGiménez, and Ríos-Rull (1999), Ventura (1999), Cassou and Lansing (2004) and Conesa and Krueger (2006), have investigated this type of reform. There are many alternative tax reforms one could consider, but our main objective is to investigate how assumptions about the production function elasticity of substitution can impact the results of policy analysis, and it is not to undertake a comprehensive policy analysis, so we only consider this one type of tax reform. Also, as before, we find that it is sufficient to understand the impact of modeling assumptions on policy by simply comparing steady states, so again we ignore the transition path between steady states.

Table 3 and Figures $2 \mathrm{a}$ and $2 \mathrm{~b}$ present some of the results for the tax reform under the different model formulations using the same reporting format as was used for the social security analysis. The tax reform is modestly more complicated than the social security reform in that it not only has a similar equilibrium effect that works through the savings channel as in the social security reform, but it also has a direct effect on labor supply because of the lower marginal tax rates. This direct effect on labor supply produces the largest impact on the equilibrium, resulting in a net increase in the life cycle labor input profiles for all agent types in both labor modeling structures. 
This can be seen in Figures $2 \mathrm{a}$ and $2 \mathrm{~b}$ by the upward shift in the equilibrium labor values across the agents' entire working career. The second effect works through the savings channel as in the social security reform and has a much smaller impact.

\section{[INSERT TABLE 3 HERE]}

To understand these effects more completely, first note that the tax reform reduces marginal tax rates and these lower marginal taxes are particularly beneficial to wealthier households who, in our model, have larger labor productivity. These lower marginal tax rates increase the desire to work which increases income and savings. As in the social security reform, the higher savings rate results in higher capital stocks, and consequently, higher marginal products of labor which encourage even greater equilibrium labor than the change in marginal tax rates would have alone. Furthermore, these increases in the capital and labor inputs have a secondary tax benefit in that they result in higher tax revenues and allow the government to raise funds required to finance public spending by setting even lower tax rates

\section{[INSERT FIGURE 2a HERE]}

As in the social security reform, the trickiest equilibrium effects occur in the labor market where all the supply and demand effects discussed before are present as well as a new incentive to work due to the lower tax rates. However, unlike the social security reform, the only labor market effect of any significance is the direct effect of the reduced tax rates on wages. Here the lower tax rates and the larger labor productivity due to higher capital accumulation, increase after-tax wages and labor supply in all the periods of the agent's working life. This can be seen in both Figures $2 \mathrm{a}$ and $2 \mathrm{~b}$.

Next consider the intertemporal substitution effect for the labor supplies. Interestingly, in the tax reform, there are two things which work to produce the intertemporal substitution for the labor supply, one of which was not present in the social security reform. The first source is the same one as in the social security reform and works through savings. In the tax reform, although the return on capital does fall because of the higher capital stock, the tax rate on capital returns is also reduced and thus the net effect on returns to savings are small. The second source for the intertemporal substitution for the labor supply arises because older workers' productivity is larger and 
they benefit more from the tax cut than younger workers. However, as shown in Figures 2a and 2b, the resulting intertemporal substitution effect for the labor supply, which was so important in the social security reform, is hardly detectable in the tax reform.

As in the social security case, the impact of the tax reform on equilibrium hours worked is the result of the interplay between the labor supply effect that we have just described and the labor demand effect. To understand the labor demand side effect, recall in the social security reform that the demand side effect arose because of changes in the $\frac{L_{1}}{L_{2}}$ ratio which changed the wage ratio between the two labor types and resulted in a feedback effect on the equilibrium. As in that reform, the ability endowment based labor structure economy implies similar life cycle changes to the after tax wage rates between the two skill types, resulting in similar changes to both unskilled and skilled labor, thus keeping the $\frac{L_{1}}{L_{2}}$ ratio approximately the same and muting the demand effect. This muted demand effect shows up in Table 3 where the tax reform shows little differences between the different $\rho$ values under the ability based labor structure.

In the experience based labor structure economy, there are larger demand effects, but they do not approach the size of those found in the social security reform. Here, the intertemporal labor substitution effect results in changes in $\frac{L_{1}}{L_{2}}$ and thus results in the demand effect working through wages. The impact of the change in $\frac{L_{1}}{L_{2}}$ can be seen in Figure $2 b$, where as in Figure $1 \mathrm{~b}$, there is a jump down in the $\rho=4$ case right at the date when agents transition from less experienced to more experienced labor. On the other hand, as in the social security reform, when young and old workers are perfect substitutes, that is $\rho=0$, relative wages do not change with $\frac{L_{1}}{L_{2}}$ and the demand effect is negligible. Although the production elasticity of substitution will have some role, both Table 3 and Figure 2 b show only small differences across the different values of $\rho$ illustrating this small demand effect.

[INSERT FIGURE 2b HERE] 


\section{Insights for other policy reforms and other modeling environments}

While our results are for two specific policy reforms and two specific modeling environments, the insights can be applied in other settings. In this section we offer a few speculations as to how these results provide insight into other modeling scenarios.

As emphasized in our discussion, one condition for the production function elasticity of substitution between the two labor types to be important is for the policy reform to result in changes in the ratio of the two types of labor inputs. It was noted for instance, in the tax reform analysis using either labor modeling structure, the two labor types where impacted in relatively equal ways, so the ratio did not change much and thus the production function elasticity of substitution had a small effect on the results. However, in the social security reform with the experience based labor structure, the reform resulted in a relatively large change in the ratio of the two labor types and thus the value of the elasticity of substitution became important. This ratio insight is likely to be useful in other settings. So for instance, in a model where human capital is acquired through schooling and policy reforms are undertaken to encourage greater numbers of college graduates, which are typically considered skilled workers, then the elasticity assumption is going to be important for the results. Similarly, in a model which may look in most ways like the ability endowment structure above, but adds the realistic feature, that skilled worker productivities grow more steadily over an agent's lifetime than unskilled workers, then policies which impact the rate of growth of the worker productivities or the life cycle labor profiles differently for the two skill types are likely to have an impact on the ratio of skilled to unskilled works and thus imply that assumptions on the elasticity of substitution between the worker types will have an impact on the results.

Another modeling assumption that may impact one's results is the labor supply elasticity. Our model assumes a popular structure used in numerous macroeconomic papers, which implies that the Frisch labor supply elasticity changes over time when an agent's supply of labor changes. Some studies, such as İmrohoroğlu and Kitao (2009) and Peterman (2013) have shown that assumptions about the Frisch labor supply elasticity can also impact the results of ones analysis. In some separate comparative static analysis not included here, we altered the utility function to a constant Frisch labor 
supply elasticity formulation. For the most part, the impact of the production function elasticity of substitution on the results of a policy reform were qualitatively the same as described above. There were some small quantitative differences in the values for the economic variables, but they were mostly small. The fact that the economic variable outcomes were largely the same, shows that the assumption about the Frisch labor supply elasticity does not impact our general conclusion that the production function elasticity of substitution between the two labor types will be important when the model and the policy reform under consideration produce a large change in the ratio of the two labor types.

\section{Conclusions}

Long lived agent overlapping generations models have shown considerable ability to offer important insights for a range of fiscal policy reforms. This ability has led to a greater interest in these models and an expansion in their modeling foundations. Currently, the modeling frontier is grappling with how to introduce worker heterogeneity in production beyond the perfectly elastic substitution case. This paper offers insight into this development by showing that the outcome of policy reform analysis may be influenced by the elasticity of substitution across different labor types in production.

Two foundations for labor types were explored over a range of production elasticities for two types of public policy analysis. It was shown that social security elimination results can be sensitive to the elasticity of substitution between more and less experienced labor, while income tax reform results were less sensitive to this production elasticity no matter what the foundation for labor productivity are. The reason for the sensitivity under an experience based labor structure has to do with the impact of the social security reform on the incentives for providing labor over an agent's lifetime and therefore on the relative supply of young labor. Under reforms in which it is attractive for households to change the relative supply of one type of labor, the results are sensitive to the production function elasticities which determine the life-cycle payoffs to labor because of a demand side feedback effect.

Although only a specific social security and a specific income tax reform were explored, the sensitivity to modeling structure likely applies to other policy reforms. Any policy reform which provides incentives for agents to change their life cycle labor profile, will find a greater sensitivity to assump- 
tions about the elasticity of substitution across labor types in the experience based labor structure because of the demand side feedback effect. Furthermore, we believe these results provide valuable insights to understanding other models which use different labor foundations altogether. We believe that as long as the policy reform results in a change in the ratio for the two labor inputs, that values for the elasticity of substitution will have quantitative implications for a policy reform analysis.

\section{References}

[1] Auerbach, A.J. and Kotlikoff, L.J., 1987. Dynamic Fiscal Policy. Cambridge University Press, Cambridge.

[2] Blankenau, W.F. and Cassou, S.P., 2010. Industry estimates of the elasticity of substitution and the rate of biased technological change between skilled and unskilled labor. Forthcoming in Applied Economics.

[3] Card, D. and Lemieux, T., 2001. Can Falling Supply Explain the Rising Return to College for Younger Men? A Cohort-Based Analysis. The Quarterly Journal of Economics, 116, 705-746.

[4] Cassou, S.P. and Lansing K.J., 2004. Growth effects of shifting from a graduated-rate tax system to a flat tax. Economic Inquiry 42, 194-213.

[5] Castañeda, A., Díaz-Giménez, J. and Ríos-Rull, J.V., 1999. Earnings and wealth inequality and income taxation: quantifying the trade-offs of switching to a proportional income tax in the U.S. Mimeo. University of Pennsylvania.

[6] Conesa, J.C., Krueger, D., 1999. Social security reform with heterogeneous agents. Review of Economic Dynamics 2, 757-795.

[7] Conesa, J.C., Krueger, D., 2006. On the optimal progressivity of the income tax code. Journal of Monetary Economics 53, 1425-1450.

[8] Fuster, L., İmrohoroğlu, A. and İmrohoroğlu, S., 2007. Elimination of social security in a dynastic framework. Review of Economic Studies 74, 113-145.

[9] Gouveia, M. and Strauss, R.P., 1994. Effective federal individual income tax functions: An exploratory empirical analysis. National Tax Journal 47, 317-339. 
[10] Hansen, G., 1983. The cyclical and secular behavior of the labor input: Comparing efficiency units and hours worked. Journal of Applied Econometrics 8, 71-80.

[11] Hansen, G. and İmrohoroğlu, S., 2009. Business cycle fluctuations and the life cycle: How important is on-the-job skill accumulation? Journal of Economic Theory 144, 2293-2309.

[12] Heckman, J., Lochner, L. and Taber, C., 1998a. Explaining rising wage inequality: explorations with a dynamic general equilibrium model of labor earnings with heterogeneous agents. Review of Economic Dynamics $1,1-58$.

[13] Heckman, J., Lochner, L. and Taber, C., 1998b. Tax policy and human capital formation. The American Economic Review 88, 293-297.

[14] Hubbard, R.G. and Judd, K.L., 1987. Social security and individual welfare: Precautionary saving, borrowing constraints, and the payroll tax. The American Economic Review 77,630 - 46.

[15] Huggett, M., 1996. Wealth distribution in life-cycle economies. Journal Monetary Economics 38, 469-494.

[16] Huggett, M., and Ventura, G., 1999. On the distributional effects of social security reform. Review of Economic Dynamics 2, 498-531.

[17] Imrohoroğlu, A. , Imrohoroğlu, S. and Joines, D. H., 1995. A life cycle analysis of social security. Economic Theory 6, 83-114.

[18] Imrohoroğlu, S. and Kitao, S., 2009. Labor supply elasticity and social security reform. Journal of Public Economics 93, 867-878.

[19] Katz, L. and Murphy, K., 1992. Changes in relative wages, 1963-1987: Supply and demand factors. Quarterly Journal of Economics 107, 35-78.

[20] Kapička, M., 2011. The Dynamics of Optimal Taxation when Human Capital is Endogenous. Mimeo.

[21] Krueger, D. and Ludwig, A. 2013. Optimal Progressive Labor Income Taxation and Education Subsidies When Education Decisions and Intergenerational Transfers Are Endogenous. American Economic Review: Papers and Proceedings, 103, 496-501

[22] Krusell, P., Ohanian, L. E., Ríos-Rull, J. and Violante, G.L., 2000. Capital-skill complementarity and inequality: A macroeconomic analysis. Econometrica 68, 1029-1053. 
[23] McGrattan, E.R. and Rogerson R., 2004. Changes in hours worked, 1950-2000. Federal Reserve Bank of Minneapolis Quarterly Review 28, $14-33$.

[24] Mendoza, E. G., Razin, A. and Tesar, L.L., 1994. Effective tax rates in macroeconomics. Cross-country estimates of tax rates on factor incomes and consumption, Journal of Monetary Economics 34, 297-323

[25] Murphy, K. M., and Welch, F., 1992. The structure of wages. Quarterly Journal of Economics 107, 285-326.

[26] Ottaviano, G. and Peri, G., 2011. Rethinking the Effect of Immigration on Wages. Forthcoming in Journal of the European Economic Association.

[27] Peterman, W., 2012. The Effect of Endogenous Human Capital Accumulation on Optimal Taxation. Mimeo.

[28] Peterman, W., 2013. Determining the motives for a positive optimal tax on capital. Journal of Economic Dynamics and Control, 37, 265-295.

[29] Rojas, J. A., 2005. Life-cycle earnings, cohort size effects and social security: A quantitative exploration. Journal of Public Economics 89, 465-485.

[30] Rojas, J. A., 2009. Social security reform with imperfect substitution between less and more experienced workers. Documentos de Trabajo. N. ${ }^{o} 0832$ Banco de España.

[31] Storesletten, K., Telmer, C.I. and Yaron, A., 2004. Consumption and risk sharing over the life cycle. Journal of Monetary Economics 51, 609633.

[32] Taber, C., 2002. Tax reform and human capital accumulation: Evidence from an empirical general equilibrium model of skill formation. Advances in Economic Analysis 85 Policy, The Berkeley Electronic Press. Article 3 .

[33] Ventura, G., 1999. Flat tax reform: A quantitative exploration. Journal of Economic Dynamics \& Control 23, 1425-1458. 
Table 1a - Common Calibration Details

\begin{tabular}{|c|c|c|}
\hline Parameter & Value & \\
\hline \multicolumn{3}{|r|}{ Common Parameter Values } \\
\hline 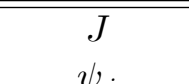 & 81 & Agents are born when they are 20 and live at most until 100. \\
\hline${ }_{j} j_{r}$ & 45 & Agents retire when they are 65 years old. \\
\hline$n$ & 0.011 & Average U.S. population growth rate. \\
\hline$\sigma$ & 2 & \\
\hline$\alpha$ & 0.36 & Share of capital income in U.S. GDP. \\
\hline$A$ & 1 & Scaling figure. \\
\hline$g$ & 0.17 & Share of government spending in U.S. Data. \\
\hline$\tau_{c, t}$ & 0.052 & Mendoza et al (1994). \\
\hline$\kappa_{0}$ & 0.258 & Gouveia and Strauss (1994). \\
\hline$\kappa_{1}$ & 0.768 & Gouveia and Strauss (1994). \\
\hline$\tau_{s s, t}$ & 0.106 & U.S. data \\
\hline$\varepsilon_{j}$ & & Hansen (1983). \\
\hline \multicolumn{3}{|r|}{ Model Specific Parameters } \\
\hline \multicolumn{3}{|r|}{ Ability Endowment Labor Structure } \\
\hline$p_{1}$ & 0.75 & Percentage of the U.S. population with less than college degree. \\
\hline$p_{2}$ & 0.25 & $p_{2}=1-p_{1}$ \\
\hline$\beta$ & 0.9943 & $\mathrm{~K} / \mathrm{Y}=3.0$ \\
\hline$\gamma$ & 0.3340 & Average hours $=0.33$ \\
\hline$\delta$ & 0.082 & $\mathrm{I} / \mathrm{Y}=0.28$ \\
\hline$\eta_{1}$ & 0.6966 & Variance of log earning at 20 years old $=0.27$ \\
\hline$\eta_{2}$ & 1.4355 & Variance of $\log$ earning at 20 years old $=0.27$ \\
\hline \multicolumn{3}{|r|}{ Experience Based Labor Structure } \\
\hline$j_{s}$ & 15 & Years of experience to become a skilled worker. \\
\hline$\beta$ & 0.9947 & $\mathrm{~K} / \mathrm{Y}=3.0$ \\
\hline$\gamma$ & 0.3332 & Average hours $=0.33$ \\
\hline$\delta$ & 0.082 & $\mathrm{I} / \mathrm{Y}=0.28$ \\
\hline$\eta_{1}$ & 1.0 & Productivity differences already captured by $\varepsilon_{j}$. \\
\hline$\eta_{2}$ & 1.0 & Productivity differences already captured by $\varepsilon_{j}$. \\
\hline
\end{tabular}


Table 1b - Model Specific Parameters

\begin{tabular}{l|cc}
\hline \hline \multicolumn{3}{c}{ Ability Endowment Labor Structure } \\
\hline \hline & $B$ & $\lambda$ \\
\hline$\rho=0$ & 2 & 0.5 \\
$\rho=0.4$ & 1.989 & 0.533 \\
$\rho=0.8$ & 1.978 & 0.566 \\
$\rho=1.2$ & 1.967 & 0.599 \\
$\rho=4$ & 1.900 & 0.791 \\
\hline \hline \multicolumn{2}{c}{ Experience Based Labor Structure } \\
\hline \hline$\rho=0$ & 2 & 0.5 \\
$\rho=0.4$ & 1.971 & 0.446 \\
$\rho=0.8$ & 1.944 & 0.393 \\
$\rho=1.2$ & 1.917 & 0.343 \\
$\rho=4.0$ & 1.777 & 0.102 \\
\hline \hline
\end{tabular}


Table 2 - Social Security Reform Results

\begin{tabular}{|c|c|c|c|c|c|c|}
\hline \multicolumn{7}{|c|}{ Ability Endowment Labor Structure } \\
\hline & BENCHMARK & \multicolumn{5}{|c|}{ NO SOCIAL SECURITY } \\
\hline & & 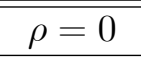 & $\rho=0.4$ & $\rho=0.8$ & $\rho=1.2$ & $\rho=4.0$ \\
\hline Output $(Y)$ & 0.76 & $+25.0 \%$ & $+25.0 \%$ & $+25.0 \%$ & $+24.9 \%$ & $+24.9 \%$ \\
\hline Capital-Output $(K / Y)$ & 3.00 & $+21.5 \%$ & $+21.5 \%$ & $+21.5 \%$ & $+21.5 \%$ & $+21.5 \%$ \\
\hline Unskilled Labor $\left(L_{1}\right)$ & 0.24 & $+14.4 \%$ & $+14.4 \%$ & $+14.4 \%$ & $+14.4 \%$ & $+14.5 \%$ \\
\hline Skilled Labor $\left(L_{2}\right)$ & 0.17 & $+8.8 \%$ & $+8.8 \%$ & $+8.8 \%$ & $+8.8 \%$ & $+8.7 \%$ \\
\hline Average hours & 0.33 & $+11.5 \%$ & $+11.5 \%$ & $+11.5 \%$ & $+11.5 \%$ & $+11.6 \%$ \\
\hline Interest rate $\%(r)$ & $3.8 \%$ & $1.7 \%$ & $1.7 \%$ & $1.7 \%$ & $1.7 \%$ & $1.7 \%$ \\
\hline Wage rate $(w)$ & 1.19 & $+1.35 \%$ & $+1.35 \%$ & $+1.35 \%$ & $+1.35 \%$ & $+1.36 \%$ \\
\hline $\operatorname{CEV}(\%)$ & & $+7.3 \%$ & $+7.0 \%$ & $+6.5 \%$ & $+6.1 \%$ & $+2.7 \%$ \\
\hline \multicolumn{7}{|c|}{ Experience Based Labor Structure } \\
\hline & BENCHMARK & \multicolumn{5}{|c|}{ NO SOCIAL SECURITY } \\
\hline & & $\rho=0$ & $\rho=0.4$ & $\rho=0.8$ & $\rho=1.2$ & $\rho=4.0$ \\
\hline Output $(Y)$ & 0.86 & $+25.5 \%$ & $+26.5 \%$ & $+27.2 \%$ & $+27.7 \%$ & $+29.8 \%$ \\
\hline Capital-Output $(K / Y)$ & 3.00 & $+21.8 \%$ & $+23.6 \%$ & $+25.0 \%$ & $+26.2 \%$ & $+30.1 \%$ \\
\hline Less Experienced Labor $\left(L_{1}\right)$ & 0.17 & $-3.5 \%$ & $-0.7 \%$ & $+1.2 \%$ & $+2.6 \%$ & $+7.0 \%$ \\
\hline More Experienced Labor $\left(L_{2}\right)$ & 0.29 & $+21.5 \%$ & $+20.1 \%$ & $+19.0 \%$ & $+18.1 \%$ & $+15.3 \%$ \\
\hline Average hours & 0.33 & $+11.3 \%$ & $+11.5 \%$ & $+11.6 \%$ & $+11.7 \%$ & $+11.8 \%$ \\
\hline Interest rate $\%(r)$ & $3.8 \%$ & $1.6 \%$ & $1.5 \%$ & $1.4 \%$ & $1.3 \%$ & $1.0 \%$ \\
\hline Wage rate $(w)$ & 1.19 & $+11.7 \%$ & $+12.6 \%$ & $+13.4 \%$ & $+14.0 \%$ & $+16.0 \%$ \\
\hline $\operatorname{CEV}(\%)$ & & $+8.7 \%$ & $+8.4 \%$ & $+8.1 \%$ & $+7.8 \%$ & $+6.8 \%$ \\
\hline
\end{tabular}


Table 3 - Proportional Tax Reform Results

\begin{tabular}{|c|c|c|c|c|c|c|}
\hline \multicolumn{7}{|c|}{ Ability Endowment Labor Structure } \\
\hline & BENCHMARK & \multicolumn{5}{|c|}{ PROPORTIONAL TAXES } \\
\hline & & $\rho=0$ & $\rho=0.4$ & $\rho=0.8$ & $\rho=1.2$ & $\rho=4.0$ \\
\hline Output $(Y)$ & 0.76 & $+6.17 \%$ & $+6.17 \%$ & $+6.17 \%$ & $+6.17 \%$ & $+6.18 \%$ \\
\hline Capital-Output $(K / Y)$ & 3.00 & $+2.41 \%$ & $+2.41 \%$ & $+2.41 \%$ & $+2.41 \%$ & $+2.41 \%$ \\
\hline Unskilled Labor $\left(L_{1}\right)$ & 0.24 & $+4.9 \%$ & $+4.9 \%$ & $+4.9 \%$ & $+4.9 \%$ & $+4.9 \%$ \\
\hline Skilled Labor $\left(L_{2}\right)$ & 0.17 & $+4.6 \%$ & $+4.6 \%$ & $+4.6 \%$ & $+4.6 \%$ & $+4.6 \%$ \\
\hline Average hours & 0.33 & $+4.6 \%$ & $+4.6 \%$ & $+4.6 \%$ & $+4.6 \%$ & $+4.6 \%$ \\
\hline Interest rate $\%(r)$ & $3.8 \%$ & $3.5 \%$ & $3.5 \%$ & $3.5 \%$ & $3.5 \%$ & $3.5 \%$ \\
\hline Wage rate $(w)$ & 1.19 & $+1.3 \%$ & $+1.3 \%$ & $+1.3 \%$ & $+1.3 \%$ & $+1.3 \%$ \\
\hline $\mathrm{CE}$ & & $+1.6 \%$ & $+1.6 \%$ & $+1.6 \%$ & $+1.6 \%$ & $+1.5 \%$ \\
\hline \multicolumn{7}{|c|}{ Experience Based Labor Structure } \\
\hline & BENCHMARK & \multicolumn{5}{|c|}{ PROPORTIONAL TAXES } \\
\hline & & $\rho=0$ & $\rho=0.4$ & $\rho=0.8$ & $\rho=1.2$ & $\rho=4.0$ \\
\hline Output $(Y)$ & 0.86 & $+6.3 \%$ & $+6.3 \%$ & $+6.3 \%$ & $+6.3 \%$ & $+6.4 \%$ \\
\hline Capital-Output $(K / Y)$ & 3.00 & $+2.0 \%$ & $+2.1 \%$ & $+2.2 \%$ & $+2.2 \%$ & $+2.4 \%$ \\
\hline Less Experienced Labor $\left(L_{1}\right)$ & 0.17 & $+3.8 \%$ & $+4.1 \%$ & $+4.3 \%$ & $+4.3 \%$ & $+4.7 \%$ \\
\hline More Experienced Labor $\left(L_{2}\right)$ & 0.29 & $+5.8 \%$ & $+5.5 \%$ & $+5.5 \%$ & $+5.4 \%$ & $+5.2 \%$ \\
\hline Average hours & 0.33 & $+5.2 \%$ & $+5.2 \%$ & $+5.2 \%$ & $+5.2 \%$ & $+5.2 \%$ \\
\hline Interest rate $\%(r)$ & $3.8 \%$ & $3.5 \%$ & $3.5 \%$ & $3.5 \%$ & $3.5 \%$ & $3.5 \%$ \\
\hline Wage rate $(w)$ & 1.19 & $+1.1 \%$ & $+1.2 \%$ & $+1.2 \%$ & $+1.2 \%$ & $+1.3 \%$ \\
\hline CEV (\%) & & $+5.7 \%$ & $+5.7 \%$ & $+5.7 \%$ & $+5.7 \%$ & $+5.8 \%$ \\
\hline
\end{tabular}


Figure 1a

Ability Endowment Labor Structure: Hours Worked by Unskilled Workers

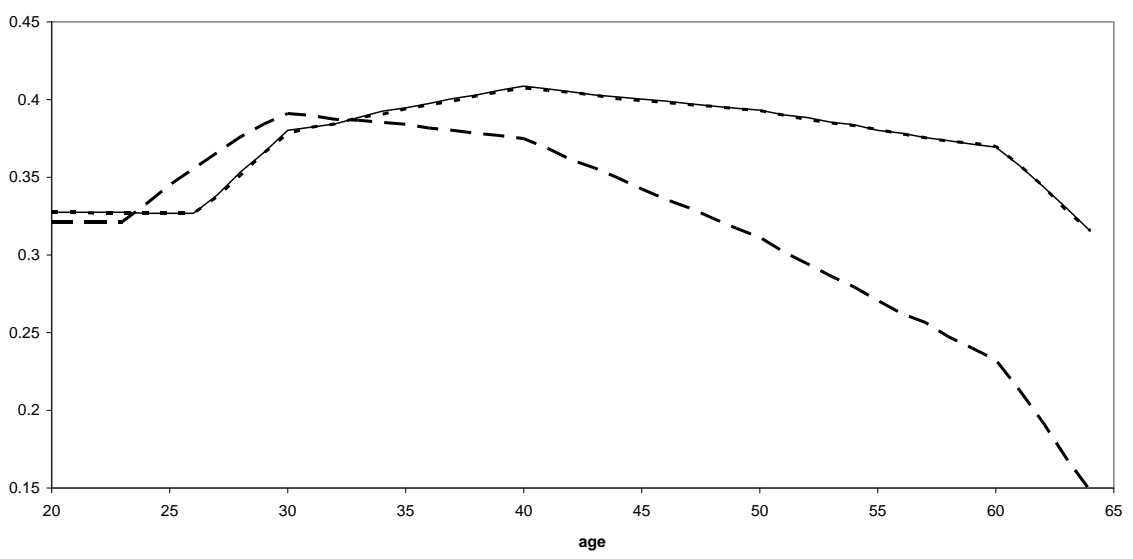

- - benchmark

- - no SS and $\rho=0$

no SS and $\rho=4$

Abiltiy Endowment Labor Structure: Hours Worked by Skilled Worker

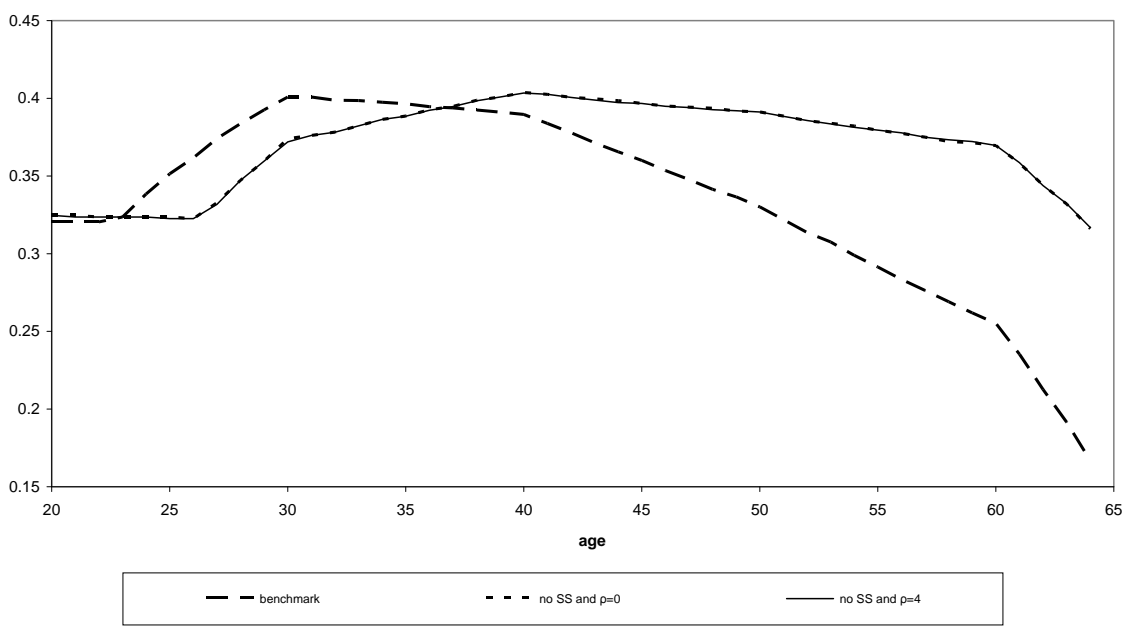


Figure 1b

Experienced Based Labor Structure: Hours Worked

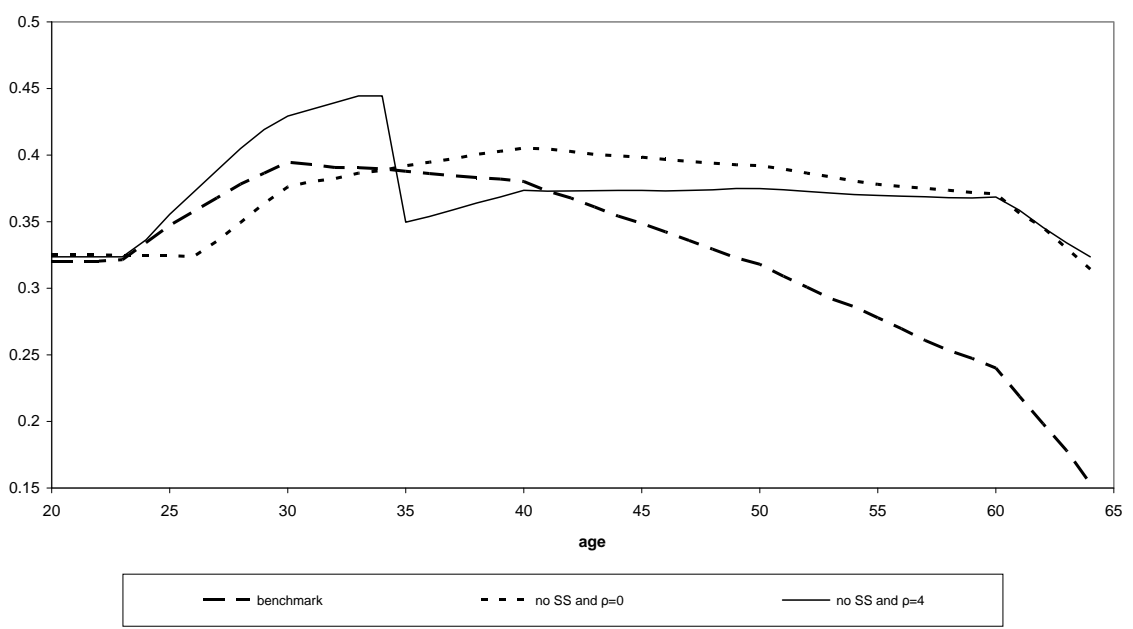


Figure 2a

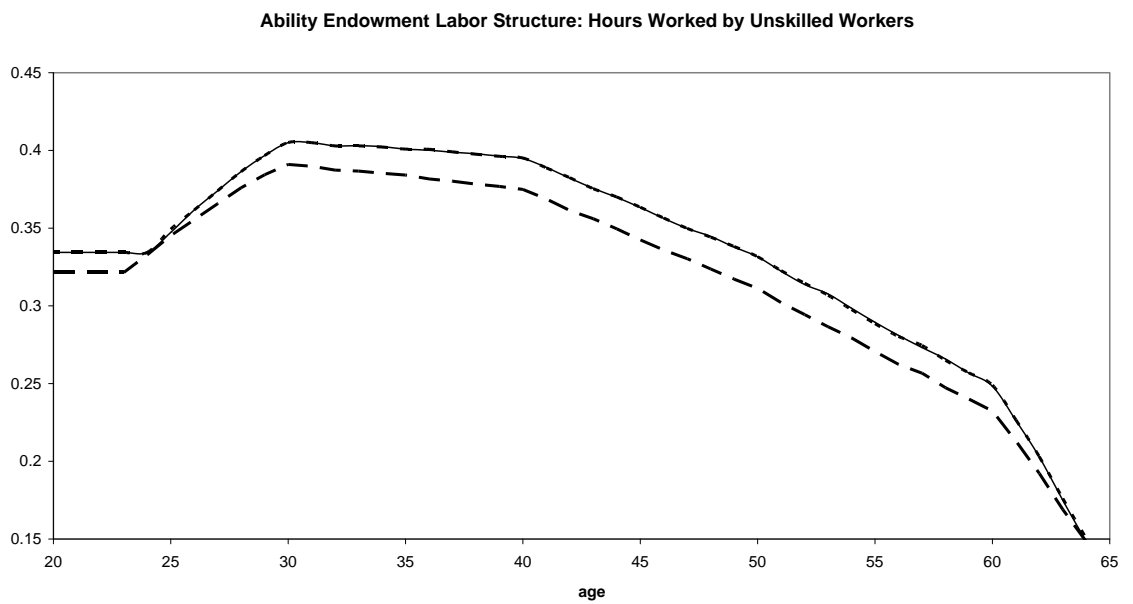

\begin{tabular}{|lll}
\hline - benchmark & $-\cdots$ & - proportional tax and $\rho=0 \quad$ p proportional tax and $\rho=4$
\end{tabular}

Ability Endowment Labor Structure: Hours Worked by Skilled Workers

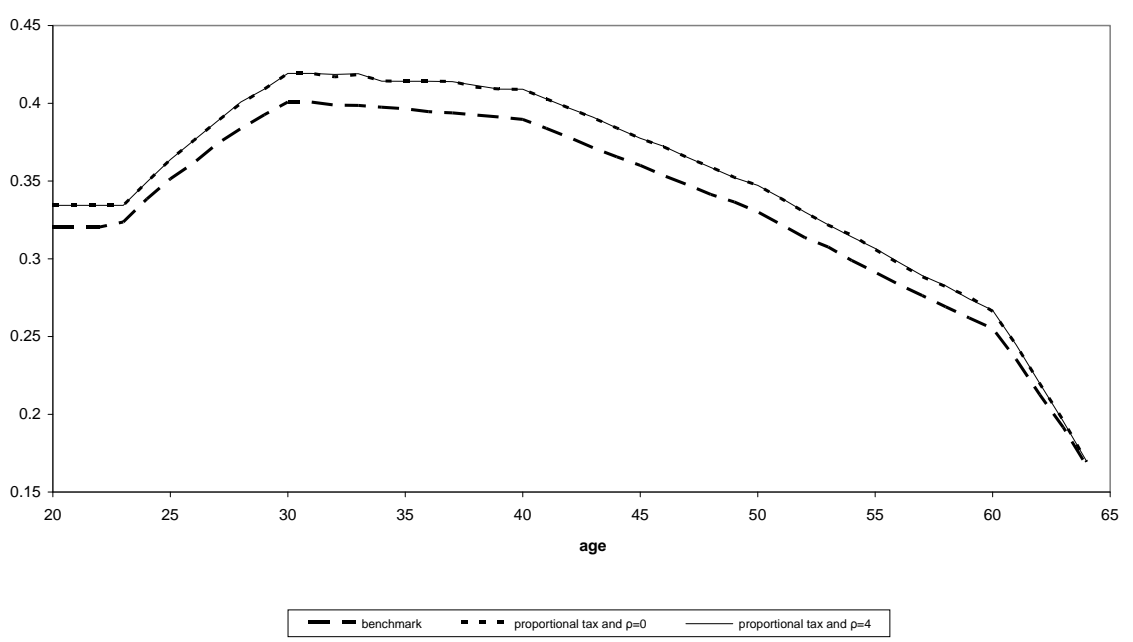


Figure $2 b$

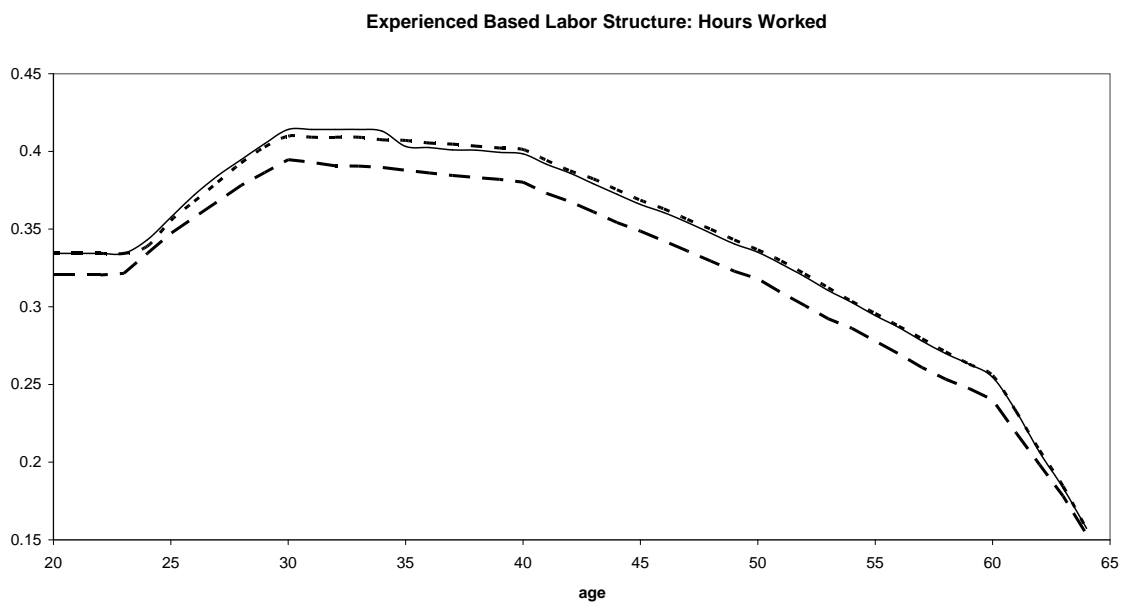

- - benchmark $\quad$ - - - proportional tax and $\rho=0 \quad$ - proportional tax and $\rho=4$ 